\title{
EVALUATION OF PHYSIOLOGICAL INTRACRANIAL CALCIFICATIONS IN CHILDREN USING COMPUTED TOMOGRAPHY
}

\author{
Katarina Raspopovic ${ }^{1}$, Valentina Opancina ${ }^{2}$, Maja Vulovic ${ }^{3}$, Slavica Markovic ${ }^{4}$, Radisa Vojinovic ${ }^{2}$ \\ ${ }^{I}$ Department of Orthopedic Surgery, Clinical Center Montenegro, Podgorica, Montenegro \\ ${ }^{2}$ University of Kragujevac, Faculty of Medical Sciences, Department of Radiology, Kragujevac, Serbia \\ ${ }^{3}$ University of Kragujevac, Faculty of Medical Sciences, Department of Anatomy, Kragujevac, Serbia \\ ${ }^{4}$ University of Kragujevac, Faculty of Medical Sciences, Department of Pediatrics, Kragujevac, Serbia
}

Received: 24.07.2019.

Accepted: 06.02.2020.

\section{Corresponding author:}

\author{
dr Valentina Opancina \\ Clinical Center Kragujevac, St. Zmaj Jovina 30, \\ Kragujevac, Serbia
}

Phone: +38162363770

E-mail: opancina.valentina@gmail.com

\section{sciendo}

UDK: 616.831-003.84-053.2-073

Eabr 2022; 23(4):339-344

DOI: $10.2478 /$ sjecr-2020-0011

\begin{abstract}
Physiological intracranial calcifications have an increasing prevalence with the age and can be found in both children and in adults. These calcifications are basically asymptomatic and their presence can only be noticed through neuro-imaging. The aim of the paper was to evaluate physiological intracranial calcifications in children using computed tomography, in our conditions. The study was designed as a retrospective, observational, nonrandomized clinical study. It was conducted at the Department of Radiology, Clinical Center Kragujevac, Serbia. The study included all the patients scanned by CT from 1st October, 2008. to 30th September, 2018.. The criteria for the inclusion were: the patients aged up to 18 years who underwent a non-contrast computed tomography in the observed period, with diagnosed intracranial calcifications that do not have pathological etiology. Our study included 420 patients. Out of them, 213 (50.7\%) were boys and 207 (49.3\%) were girls. The mean age was 12.47. We divided the patients into two age categories: the first one included the patients aged 1 to 10 years and the other one included the patients aged 11 to 18 years. Our study has demonstrated that physiological intracranial calcifications are the most frequent in habenula (28.1\%), followed by the pineal gland (22.6\%) and choroid plexus $(18.8 \%)$. There is a small number of studies with the subject of physiological intracranial calcification distribution, especially in children. It is important to know in which locations we can expect physiological intracranial calcifications, as well as the age in which they become detectable by imaging, in order not to mix them with hemorrhages, pathological tumor or metabolic mineralization.
\end{abstract}

Keywords: Physiological intracranial calcification, computed tomography, children, pineal gland, habenula, choroid plexus. 


\section{INTRODUCTION}

Intracranial calcifications (IC) may be pathological and physiological $(1,2)$. Pathological calcifications, depending on the etiology, are classified as: infectious, endocrine and metabolic, vascular, neoplastic and congenital (3). There are also IC in which there is no evidence of a disease, they have no pathological cause and are classified as physiological intracranial calcifications (PIC) $(2,4)$. PIC arise due to the formation of deposits of calcium and iron in the blood vessels of various brain structures (5). These calcifications are basically asymptomatic and their presence can only be noticed through neuro-imaging. Computed tomography (CT) is still the gold standard and the most sensitive modality in IC diagnostics (6).

Physiological intracranial calcifications have an increasing prevalence with the age and can be found in both children and in adults. PIC can be found at the following locations: the pineal gland, choroid plexus, basal ganglia, falx, tentorium cerebelli, lens, petroclinoid ligament, dura mater, sagittal sinus and habenula $(1,7)$. Calcifications in the epiphysis (also referred as the pineal gland) appear from the fetal age, they are seen in two-thirds of the adults and their incidence increases over the years. Pineal calcifications that are greater than $1 \mathrm{~cm}$ in diameter or occur in children under 9 years of age may indicate a neoplasm $(8,2)$. Habenular calcification occurs in $15 \%$ of the elderly population and PIC in the basal ganglia have the incidence of $0.3 \%$ to $1.5 \%$. Other locations have a total frequency of about $10 \%$ in the elderly (3). Before, it was thought that pineal calcification in children under 6 years of age is always pathological, but this does not apply in the modern era of CT. A study dealing with PIC prevalence in children showed that epithalamus (epiphysis and /or habenula) calcification occurred in $13 \%$ (63/500), and pineal in $5 \%$, horrible in $12 \%(9)$. A significant association between the patients with choroid and pineal calcifications in children $(\mathrm{p}=0.003)$ was reported $(9)$.

There is a small number of studies with the subject of PIC distribution, especially in children. It is important to know in which locations we can expect physiological intracranial calcifications, as well as the age in which they become detectable by imaging, in order not to mix them with hemorrhages, pathological tumor or metabolic mineralization $(10,11,12$, 13,14).

The aim of this study is to evaluate physiological intracranial calcifications in children using computed tomography, in our conditions.

\section{MATERIAL AND METHODS}

The study was designed as a retrospective, observational, non-randomized clinical study. It was conducted at the Department of Radiology, Clinical Center Kragujevac, Serbia, and encompassed all the patients scanned by CT from 1st October, 2008 . to 30th September, 2018.
The criteria for the inclusion were: the patients aged up to 18 years who underwent a noncontrast computer tomography in the observed period, with diagnosed intracranial calcifications that do not have pathological etiology. The follow-up CT scans were not taken into account.

The presence of intracranial calcification on the computed tomography scans is defined as hyperatenuated matter in comparison to the gray matter. The diagnosis of IC was made by two radiologists with the experience in $\mathrm{CT}$ reading for 20 years.

The exclusion criteria were: pathological etiology, CT scans with artifacts, the use of contrast media, the patients who underwent surgery, presence of bleeding or neoplasms on CT which made the visualization of IC more difficult.

Imaging for all the patients was done on 64-slice MDCT (Aquilion 64, Toshiba, Japan). CT scans were done in the axial plane, with multiplanar reconstructions and 3D reconstructions. The analysis of the scans and MDCT data was done on the work station Vitrea 2 Workstation ver.4.1.14.0 (Vital-Images), while using commercially available software (Imaging Software ver.4.1.14.0, Vital-Images, Canon Group, USA).

The data were collected in Microsoft Office Excel and transferred to the SPSS (SPSS 21.0; IBM, Armonk, New York) for the analysis. The statistical analysis of the data was accomplished primarily with descriptive statistics. The correlations were made by using the Pearson product-moment correlation coefficient where $\mathrm{p}$ value less than 0.05 was considered significant.

\section{RESULTS}

Our study included 420 patients. Out of them, 213 $(50.7 \%)$ were boys and 207 (49.3\%) were girls . The mean age was 12.47 . We divided the patients into two age categories: the first one included the patients aged 1 to 10 years and the other one included the patients aged 11 to 18 years. The prevalence of physiological intracranial calcifications on the explored locations, as well as their distribution by the gender and age are shown in Table 1.

Our results have shown that there is a significant correlation between pineal and habenular PIC $(\mathrm{p}=0.003)$, pineal and sagital sinus PIC $(p=0.009)$ and tentorium cerebelli and petroclinoid $\mathrm{PIC}(\mathrm{p}=0.000)$.

It has also been shown that there is a positive corretlation between the patients' age and presence of PIC $(\mathrm{p}=0.001)$. Intracranial calcifications were more frequent in older children, who were between 11 and 18 years old. Out of nine explored locations on computed tomography, two (basal ganglia and dura mater) showed no presence of PIC. Also, four examined 
locations didnt have calcifications in children who were 10 years old and younger (Table 1).

Distribution of physiological intracranial calcifications in children depending on the age group are shown in Figure1, Figure 2 and Figure 3.

Figure 1. Chart shows the distribution of PIC in explored locations depending on age

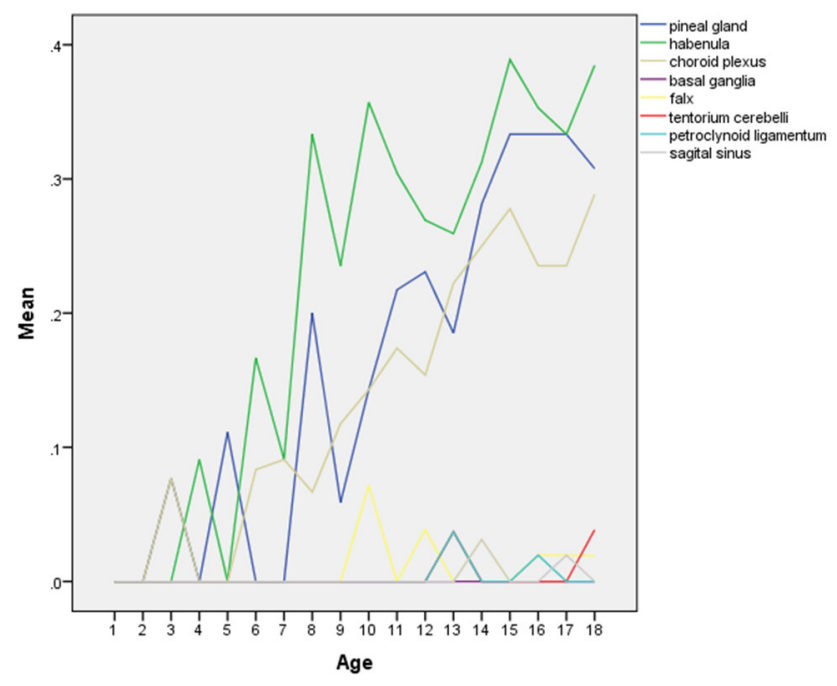

Figure 2. Distribution of pineal gland PIC by two age groups

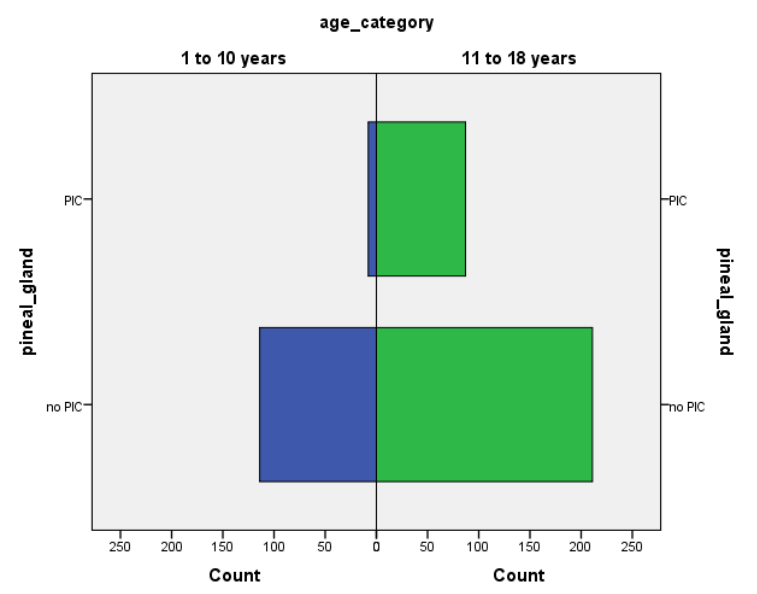

Figure 3. Distribution of habenular PIC by two age groups

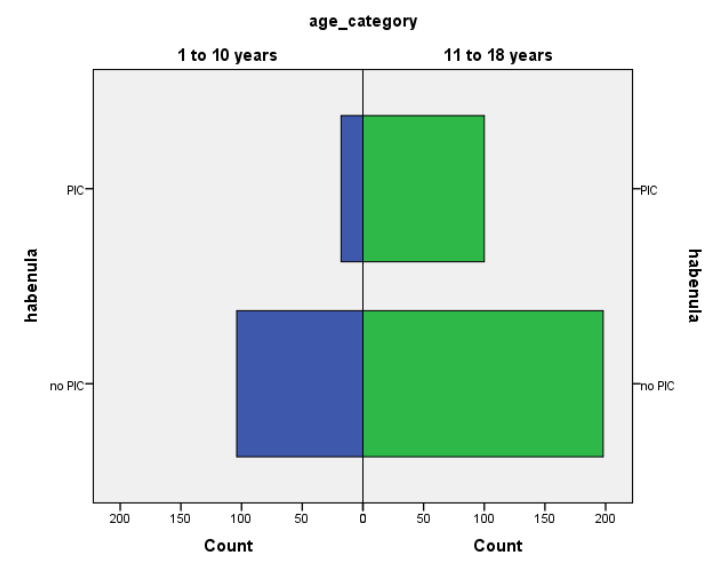

Table 1. Prevalence and distribution of the physiological intracranial calcifications on the explored locations by gender

\begin{tabular}{|c|c|c|c|c|}
\hline PIC & $\begin{array}{c}\text { Prevalence } \\
\text { n, \% }\end{array}$ & $\begin{array}{c}\text { Gender } \\
\text { n, } \%\end{array}$ & $\begin{array}{c}\text { Age from } 1 \text { to } 10 \\
n, \%\end{array}$ & $\begin{array}{c}\text { Age from } 11 \text { to } 18 \\
n, \%\end{array}$ \\
\hline Pineal gland & $95(22.6 \%)$ & $\begin{array}{c}\text { m: } 52(54.7 \%) \\
\text { f: } 43(45.3 \%)\end{array}$ & $8(1.9 \%)$ & $87(20.71 \%)$ \\
\hline Habenula & $118(28.1 \%)$ & $\begin{array}{l}\text { m: } 66(55.9 \%) \\
\text { f: } 52(44.1 \%)\end{array}$ & $18(4.28 \%)$ & $100(23.81 \%)$ \\
\hline $\begin{array}{l}\text { Choroid } \\
\text { plexus }\end{array}$ & $79(18.8 \%)$ & $\begin{array}{c}\text { m: } 33(41.8 \%) \\
\text { f: } 46(58.2 \%)\end{array}$ & $8(1.9 \%)$ & $71(16.9 \%)$ \\
\hline Basal ganglia & 0 & $\begin{array}{l}\mathrm{m}: 0 \\
\mathrm{f}: 0\end{array}$ & 0 & 0 \\
\hline Falx & $6(1.4 \%)$ & $\begin{array}{c}\text { m: } 2(33.3 \%) \\
\text { f: } 4(66.7 \%)\end{array}$ & $1(0.24 \%)$ & $5(1.19 \%)$ \\
\hline $\begin{array}{l}\text { Tentorium } \\
\text { cerebelli }\end{array}$ & $3(0.7 \%)$ & $\begin{array}{c}\text { m: } 0 \\
f: 3(100 \%)\end{array}$ & 0 & $3(0.71 \%)$ \\
\hline
\end{tabular}




\begin{tabular}{|l|c|c|c|c|}
\hline \multicolumn{1}{|c|}{ PIC } & $\begin{array}{c}\text { Prevalence } \\
\mathbf{n}, \%\end{array}$ & $\begin{array}{c}\text { Gender } \\
\mathbf{n}, \mathbf{\%}\end{array}$ & $\begin{array}{c}\text { Age from } \mathbf{1} \text { to 10 } \\
\mathbf{n ,} \%\end{array}$ & $\begin{array}{c}\text { Age from 11 to 18 } \\
\mathbf{n , \%}\end{array}$ \\
\hline $\begin{array}{l}\text { Petroclynoid } \\
\text { ligamentum }\end{array}$ & $2(0.5 \%)$ & $\begin{array}{c}\mathrm{m}: 1(50 \%) \\
\text { f: } 1(50 \%)\end{array}$ & 0 & $2(0.48 \%)$ \\
\hline Sagital sinus & $2(0.5 \%)$ & $\begin{array}{c}\mathrm{m}: 2(100 \%) \\
\text { f: } 0\end{array}$ & 0 & $2(0.48 \%)$ \\
\hline Dura matter & 0 & $\begin{array}{c}\mathrm{m}: 0 \\
\text { f: } 0\end{array}$ & 0 & 0 \\
\hline
\end{tabular}

Typical presentation of physiological intracranial calcifications in children are presented in Picture 1 and Picture 2.

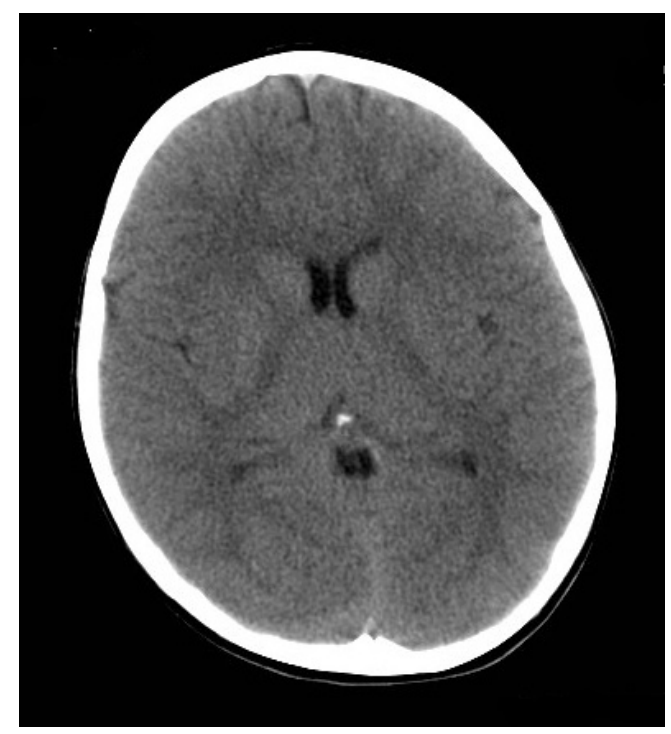

Figure 1. Habenular IC in 7 year old girl

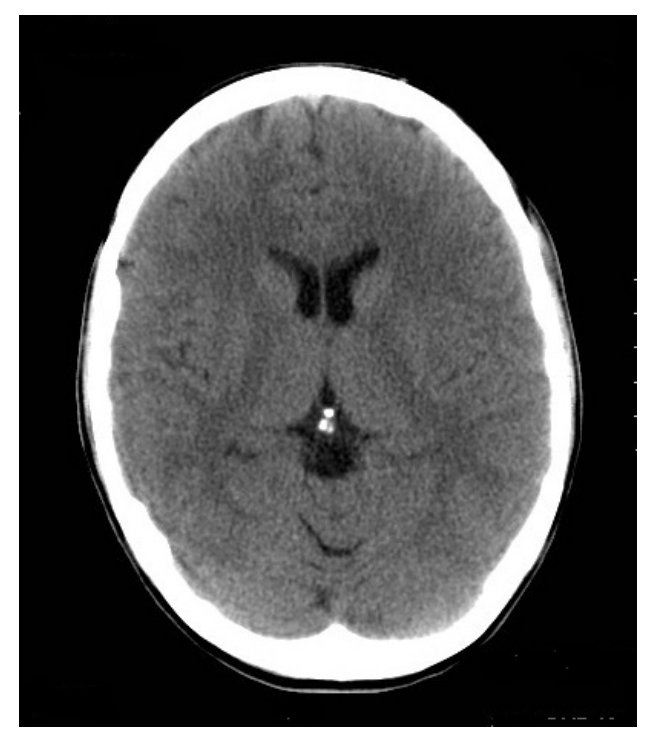

Figure 2. Pineal and habenular IC in 14 year old boy

\section{DISCUSSION}

Our study has demonstrated that physiological intracranial calcifications are most frequent in habenula $(28.1 \%)$, followed by the pineal gland $(22.6 \%)$ and choroid plexus $(18.8 \%)$. Because of that, these three locations would be thoroughly discussed.

The previous study presented that PIC in habenula had the prevalence of $10 \%$ (the total number of patients was 500 ) and none younger than 2 years $(9,15)$. Our prevalence was higher and our youngest patient with habenular PIC was 4 years old. Our study also showed a positive correlation between habenular and pineal PIC, which is understandable, due to their location and closeness $(16,17)$.

Unlike habenula, there are more published data regarding pineal PIC in children. The prevalence of the patients younger than 10 years, was $8 \%$, where the minimum age was $3(15)$. The other one presented the prevalence of $5 \%$ and the minimum age was also 3 (9). In an older study, $3 \%$ of pineal PIC were found in babies before their first birthday (18). The prevalence of pineal PIC in our study was higher $(22.6 \%)$, but our youngest patient was also 3 years old. The difference in the prevalence can be described by the age limit in the studies and different CT scanner. Some of the studies explored the patients from the birth, while others used the first birthday as the lower age limit. Few studies only explored the patients younger than 10 or 11 years. Also, the upper age limit varied from 15 to 20 years. Due to that, the incidence and other data varied from study to study. In addition to this, the technological advance of computed tomography allowed better resolution and more slices which enabled better diagnostic possibilities.

Choroid plexus PIC were the third most common PIC in our study $(18.8 \%)$. The previous published data vary regarding this location $(19,20,21,22)$. More recent studies reported the prevalence of $16 \%$ and $12 \%(9,19)$. Older studies had the prevalence of $0.5 \%$ in the first decade and $2 \%$ in the patients younger than 8 years $(20,21)$. Our youngest patient was 3 years old. The prevalence in the first decade was $1.9 \%$ which is similar to the results published in 1980 and 1986. We haven't found a positive correlation between choroid plexus and pineal PIC which was reported previously $(9,15)$. 


\section{CONCLUSION}

There are very scarce data on physiological intracranial calcifications, seen by CT in children (23). However, these findings should be given more thought, especially due to the fact that its prevalence increases with the age. It would be important to follow up children with physiological intracranial calcifications and see if there is a long term correlation with other conditions and calcifications (24).

Also, other imaging modalities, like magnetic resonance imaging should be used (25-27).

This would require a large multicentric study and these results would give us better perspective for the clinical significance of physiological intracranial calcifications, which is why we recommend further investigations with this topic.

\section{ETHICS APPROVAL}

The study was conducted in accordance with the ethical standards of the committee responsible for human experimentation (institutional and national) and the Helsinki Declaration of 1975, as revised in 2013.

\section{CONFLICT OF INTEREST}

The authors declare no conflict of interest.

\section{FUNDING}

None.

\section{REFERENCES}

1. Erdem E, Ağildere M, Eryilmaz M, Ozdirim E. Intracranial calcification in children on computed tomography. Turk J Pediatr. 1994; 36(2):111-22.

2. Uduma FU, Pius F, Mathieu M. Computed tomographic pattern of physiological intracranial calcifications in a city in central Africa. Glob J Health Sci. 2012; 4(1):18491.

3. Kıroğlu Y, Callı C, Karabulut N, Oncel C. Intracranial calcifications on CT. Diagn Interv Radiol. 2010;16(4):263-9.

4. Sedghizadeh PP, Nguyen M, Enciso R. Intracranial physiological calcificationsevaluated with cone beam CT. Dentomaxillofac Radiol. 2012 Dec;41(8):675-8.

5. Deepak S, Jayakumar B, Shanavas. Extensive intracranial calcification. $\mathrm{J}$ Assoc Physicians India. 2005;53:948

6. Yalcin A, Ceylan M, Bayraktutan OF, Sonkaya AR, Yuce I. Age and gender related prevalence of intracranial calcifications in CT imaging; data from 12,000 healthy subjects. J Chem Neuroanat. 2016;78:20-24.

7. Daghighi MH, Rezaei V, Zarrintan S, Pourfathi H. Intracranial physiological calcifications in adults on computed tomography in Tabriz, Iran. Folia Morphol(Warsz). 2007;66(2):115-9.

8. Turgut AT, Karakaş HM, Ozsunar Y, Altın L, Ceken K, Alıcıoğlu B, Sönmez I, Alparslan A, Yürümez B, Celik T, Kazak E, Geyik PÖ, Koşar U. Age-related changesin the incidence of pineal gland calcification in Turkey: A prospective multicenter CT study. Pathophysiology. 2008;15(1):41-8.

9. Whitehead MT, Oh C, Raju A, Choudhri AF. Physiologic pineal region, choroid plexus, and dural calcifications in the first decade of life. AJNR Am J Neuroradiol. 2015;36(3):575-80.

10. Ciraci S, Gumus K, Doganay S, Dundar MS, Kaya Ozcora GD, Gorkem SB, Per H, Coskun A. Diagnosis of intracranial calcification and hemorrhage in pediatric patients: Comparison of quantitative susceptibility mapping and phase images of susceptibility-weighted imaging. Diagn Interv Imaging 2017; 98(10):707-714.

11. Tonduti D, Panteghini C, Pichiecchio A, Decio A, Carecchio M, Reale C, Moroni I, Nardocci N, Campistol J, Garcia-Cazorla A, Perez Duenas B; Cerebral Calcification International Study Group, Chiapparini L, Garavaglia $\mathrm{B}$, Orcesi S. Encephalopathies with intracranial calcification in children: clinical and genetic characterization. Orphanet J Rare Dis 2018; 13(1):135.

12. Chen W, Zhu W, Kovanlikaya I, Kovanlikaya A, Liu T, Wang S, Salustri C, Wang Y. Intracranial calcifications and hemorrhages: characterization with quantitative susceptibility mapping. Radiology 2014; 270(2):496-505.

13. Özgür A, Esen K. Ossification of the petrosphenoidal ligament: multidetector computed tomography findings of an unusual variation with a potential role in abducens nerve palsy. Jpn J Radiol 2015; 33(5):260-5. 
14. Gumus K, Koc G, Doganay S, Gorkem SB, Dogan MS, Canpolat M, Coskun A, Bilgen M. Susceptibility-Based Differentiation of Intracranial Calcification and Hemorrhage in Pediatric Patients. J Child Neurol 2015; 30(8):1029-36.

15. Doyle AJ, Anderson GD. Physiologic calcification of the pineal gland in children on computed tomography: prevalence, observer reliability and association with choroid plexus calcification. Acad Radiol 2006; 13:822-26.

16. Mutalik S, Tadinada A. Prevalence of pineal gland calcification as an incidental finding in patients referred for implant dental therapy. Imaging Sci Dent 2017; 47(3):175-180.

17. Tan DX, Xu B, Zhou X, Reiter RJ. Pineal Calcification, Melatonin Production, Aging, Associated Health Consequences and Rejuvenation of the Pineal Gland. Molecules 2018; 23(2). pii: E301.

18. Helmke K, Winkler P. Incidence of pineal calcification in the first 18 years of life. Rofo 1986; 144:221-26.

19. Korzhevskii DE. The formation of psammomabodies in the choroid plexus of the human brain. Morfologiia 1997; 111:46-49.

20. Kendall B, Cavanagh N. Intracranial calcification in paediatric computed tomography. Neuroradiology 1986; 28:324-30.

21. Modic MT, Weinstein MA, Rothner AD, et al. Calcification of the choroid plexus visualized by computed tomography. Radiology 1980; 135:369-72.

22. Madhukar M, Choudhary AK, Boal DK, Dias MS, Iantosca MR. Choroid plexus: normal size criteria on neuroimaging. Surg Radiol Anat 2012; 34(10):887-95.
23. Livingston JH, Stivaros S, Warren D, Crow YJ. Intracranial calcification in childhood: a review of aetiologies and recognizable phenotypes. Dev Med Child Neurol 2014; 56(7):612-26.

24. La Piana R, Uggetti C, Roncarolo F, Vanderver A, Olivieri I, Tonduti D, Helman G, Balottin U, Fazzi E, Crow YJ, Livingston J, Orcesi S. Neuroradiologic patterns and novel imaging findings in Aicardi-Goutières syndrome. Neurology 2016; 86(1):28-35.

25. Choudhri AF, Whitehead MT, Siddiqui A, Klimo P Jr, Boop FA. Diffusion characteristics of pediatric pineal tumors. Neuroradiol J 2015; 28(2):209-16.

26. Adams LC, Bressem K, Böker SM, Bender YY, Nörenberg D, Hamm B, Makowski MR. Diagnostic performance of susceptibility-weighted magnetic resonance imaging for the detection of calcifications: A systematic review and meta-analysis. Sci Rep 2017; 7(1):15506.

27. Adams LC, Böker SM, Bender YY, Diederichs G, Fallenberg EM, Wagner M, Hamm B, Makowski MR. Diagnostic accuracy of susceptibility-weighted magnetic resonance imaging for the evaluation of pineal gland calcification. PLoS One 2017; 12(3):e0172764. 